\title{
FORMULATION, DEVELOPMENT AND OPTIMIZATION OF MODIFIED RELEASING PELLETS OF DRUG CARVEDILOL
}

\author{
Available online at www.ijdra.com \\ RESEARCH ARTICLE \\ ${ }^{1}$ Kurnool Abdul Nasir *, ${ }^{1}$ Jat Rakesh Kumar, ${ }^{2}$ Narendra C \\ ${ }^{1}$ Institute of Pharmacy, Shri JJT University, Jhunjhunu (Raj) India. \\ ${ }^{2}$ Viswesvarapura Institute of Pharmaceutical Sciences, Bangalore, India. \\ *Corresponding Author's E-mail: nasirmpharma@gmail.com
}

DOI: https://doi.org/10.22270/ijdra.v5i4.208

\begin{abstract}
The main objectives of present work was to design and evaluate modified releasing pellets of drug, Carvedilol, in respect to increase patient compliance and therapeutically benefits. The modified releasing pellets were made by the sub-coating with sodium bicarbonate and hydroxyl propyl methyl cellulose which was utilized to keep the spheres in stomach for long time. To get modified release of active pharmaceutical ingredients from the pelletizing process, they were coated with methacrylic acid co-polymer (Eudragit NE 40D). Hence sodium bicarbonate, hydroxyl propyl methyl cellulose and eudragit NE 40D are the key ingredients of this dissertation work. Concentration of sodium bicarbonate, hydroxyl propyl methyl cellulose and eudragit NE 40D in coating suspension was optimized by initial studies and factorial design. The procedure based optimization analysis also perform to optimize process factors like product temperature and spraying rate to improve physical parameters and micromeritic characteristics of spheres by preliminary data.
\end{abstract}

Keywords: Carvedilol, Eudragit, Multiparculate, Thin layer chromatography, High performance liquid chromatography.

\section{INTRODUCTION}

Carvedilol is antihypertensive drug used for mild to moderate hypertension. It is beta blocker with additional alpha 1 blocking activity. It is administer orally and is immediately absorb from GIT. Peak medication impacts occur in 90 min of single units. In single unit study, in subjects administering with $5 \mathrm{mg}$ and $10 \mathrm{mg}$ drug, the mean peak concentrations $\left(\mathrm{C}_{\max }\right)$ were 59 (range: 29-112) and 121 (range: 58-271) $\mathrm{ng} / \mathrm{mL}$, respectively, occurs at a mean time $\left(\mathrm{T}_{\max }\right)$ of $1.6 \mathrm{~h}$ for both strengths.<smiles>COc1ccccc1OCCNCC(O)COc1cccc2[nH]c3ccccc3c12</smiles>

1-(9H-Carbazol-4-yloxy)-3-[[2-(2-methoxy phenoxy) ethyl]-amino]- 2-propanol

Multiparticulate drug shipping device (MDDS), have been extensively used for administering via oral path, it includes wide variety of smaller discrete subunits which has exceptional homes. It's specifically primarily based on subunits like microspheres $(1,2)$, granules, pellets, beads minitab and spheroids. (3-5) Such kind of subunits gives numerous advantages as evaluate to monolithic kind gadgets. In MDDS, active pharmaceutical substances are get divides into range of subunits, usually which has number of round units which have diameter of about 0.052 $\mathrm{mm}$ to $1.98 \mathrm{~mm}$. to make use of or to administer total dose these subunits to be compacted in capsules or get crammed right into an optimistic packs or well encapsulated. (6)

The composition including multicomponent MDDS is feasible as it famous numerous mode of movement, it shows synergistic or additive effect, minimizes man or woman's doses and limit the facet results. Though its miles more luxurious as compare to single treatment options within the quick term, it minimizes treatment failure ratio, reduce charge of case fatality and drop in improvement of resistance for designing 
of recent devices in long time type therapy. (7, 8)

Various formulation parameters that play a crucial role in the successful formulation of drugs are aqueous solubility, stability at ambient temperature and humidity, photo stability, compatibility with solvent and excipients. (9)

Multiple unit dosage units are pharmaceutical compositions in that the lively substance is available as a spread of smaller independent multiple devices. To provide the recommended each day dose, these form of small units are get well stuffed into a normal sachet and compressed or encapsulated right into a strong dosage shape. A couple of units are discrete small debris which give the multiple unit kind system. Additionally they display range of benefits over single-unit kind systems due to of their very smaller length. A couple of gadgets are much less depending on gastric emptying, which ends up in minimal intra and inter -issue type variant in gastro-intestinal transit kind. They also uniformly disbursed and really minimum assume to reason nearby type irritation.

There are a couple of justifications for designing a active substance as a multiple unit gadget for e.g., to improve disintegration type inside the belly, or to show provide a comfortable, fast disintegrating kind tablet which get dissolve in aqueous medium early to swallowing which also can useful resource compliance with elder volunteers and small Childs. Multiple unit device gives well reproducible pharmacokinetic sample than monolithically or conventional formulations. After process of disintegration which observes inside a very much less minutes even in seconds, the character subunits get bypass immediately via a GI tract. If those debris or units have diameter not $>1.99 \mathrm{~mm}$, they have potential to left the stomach in nonstop way, even though the pylorus is being closed. These results in much less inter and intra subject versions in bioavailability and plasma stages. The main objectives of present work was to design and evaluate modified releasing pellets of drug, Carvedilol, in respect to increase patient compliance and therapeutically benefits.

\section{MATERIALS AND METHODS}

The following materials were used for the experimental work done.

Table 1: List of Chemicals used

\begin{tabular}{|c|c|c|c|}
\hline S.N. & $\begin{array}{l}\text { Name of } \\
\text { chemical }\end{array}$ & Grade & $\begin{array}{c}\text { Manufacturer / } \\
\text { Distributor }\end{array}$ \\
\hline 1 & Carvedilol & USP & $\begin{array}{c}\text { Aurobindo } \\
\text { Pharma, } \\
\text { Hyderabad }\end{array}$ \\
\hline 2 & $\begin{array}{l}\text { Eudragit } \\
\text { NE 40D }\end{array}$ & - & $\begin{array}{c}\text { Degussa Evonik } \\
\text { India }\end{array}$ \\
\hline 3 & $\begin{array}{l}\text { HPMC } \\
\text { E5LV }\end{array}$ & $\begin{array}{l}\text { USP/NF, } \\
\text { EP,JP }\end{array}$ & $\begin{array}{c}\text { Signet } \\
\text { Chemical } \\
\text { Corporation, } \\
\text { Mumbai }\end{array}$ \\
\hline 4 & $\begin{array}{c}\text { Low } \\
\text { substituted } \\
\text { HPC E5LV }\end{array}$ & $\begin{array}{l}\text { USP/NF, } \\
\text { JP }\end{array}$ & $\begin{array}{c}\text { Signet } \\
\text { Chemical } \\
\text { Corporation, } \\
\text { Mumbai }\end{array}$ \\
\hline 5 & PEG 6000 & LR & $\begin{array}{c}\text { Clariant } \\
\text { chemicals India } \\
\text { Ltd, India }\end{array}$ \\
\hline 6 & $\begin{array}{l}\text { Sodium } \\
\text { Lauryl } \\
\text { Sulphate }\end{array}$ & AR & $\begin{array}{c}\text { Signet } \\
\text { Chemical } \\
\text { Corporation, } \\
\text { Mumbai }\end{array}$ \\
\hline 7 & PVP K 30 & LR & $\begin{array}{c}\text { Signet } \\
\text { Chemical } \\
\text { Corporation, } \\
\text { Mumbai }\end{array}$ \\
\hline 8 & Talc & LR & $\begin{array}{l}\text { S.D. Fine } \\
\text { Chemicals Ltd., } \\
\text { Mumbai, India }\end{array}$ \\
\hline 9 & $\begin{array}{l}\text { Isopropyl } \\
\text { Alcohol }\end{array}$ & AR & $\begin{array}{l}\text { Loba Chemie } \\
\text { Pvt. Ltd., } \\
\text { Mumbai, India. }\end{array}$ \\
\hline 10 & $\begin{array}{c}\text { Sodium } \\
\text { Bicarbonate }\end{array}$ & $\mathrm{AR}$ & $\begin{array}{c}\text { Allied } \\
\text { Overseas, } \\
\text { Mumbai, India }\end{array}$ \\
\hline
\end{tabular}

\section{Pre-formulation Study}

\section{Melting point determination}

Drug substance melting point was checked by using capillary method. Observed value was compared with the reported value.

\section{Scanning of Carvedilol tartrate in $0.01 \mathrm{~N} \mathrm{HCl}$}

The solution having $10 \mu \mathrm{g} / \mathrm{ml}$ of Carvedilol tartrate in $0.01 \mathrm{~N} \mathrm{HCl}$ was manufactured and 
scan over the wavelength range of $200-400 \mathrm{~nm}$ against $0.01 \mathrm{~N} \mathrm{HCl}$ as blank utilizing UV spectrophotometer. A plot of wavelength verses absorbance was recorded using UV spectrophotometer.

\section{Standard curve of Carvedilol in $0.01 \mathrm{~N} \mathrm{HCl}$}

A correct weighing quantity of Carvedilol (10 $\mathrm{mg}$ ) was dissolve in $100 \mathrm{ml}$ of $0.01 \mathrm{~N} \mathrm{HCl}$ to give a stock solution $(100 \mu \mathrm{g} / \mathrm{ml})$. The stocks solution is used to investigate the $\lambda$ max of Carvedilol. The aliquots $(0.2-2 \mathrm{ml})$ of the stock solution which further diluted to $10 \mathrm{ml}$ to manufacture standard solutions which have concentrations of $2-20 \mu \mathrm{g} / \mathrm{ml}$. The absorbance of solvents was calculated at $294.5 \mathrm{~nm}$ utilizing double beam UV-Visible spectrophotometer against $0.01 \mathrm{~N} \mathrm{HCl}$ as a blank. The plot of absorbances verses concentration $(\mu \mathrm{g} / \mathrm{ml})$ was plotted and results were subjected for linear regression study in MS Excel. Curve shown in figure 1 .

\section{Drug-Excipients interaction study}

\section{FTIR spectroscopy}

Infrared spectra-photometry is a useful analytical tool to check chemical interactive action in active substance and various ingredients utilized in composition. A sample (1 $\mathrm{mg}$ ) was mixed and powdered with $10 \mathrm{mg}$ dry powdered of $\mathrm{KBr}$. The mixing of powder was bringing in a sample and the spectrums were determined by screening in wavelength range of $400-4000 \mathrm{~cm}^{-1}$ using FTIR spectrophotometer. The drugs IR spectrum was compared with physical mix of drug and polymers to found for such possible active substance-excipients interaction.

\section{Differential Scanning Calorimetry (DSC)}

A DSC (Mettler Toledo, Greifensee, Switzerland) is equipped with an intra-cooler device and refrigerating system was utilized to analyze thermal characteristics of Carvedilol. Active substance loaded pellets and Eudragit coated pellet in the range of 35 to $300^{\circ} \mathrm{C}$. Indium standard were utilized to calibrate temperature of DSC. Nitrogen gas was purging at $50 \mathrm{ml} / \mathrm{min}$ and $100 \mathrm{ml} / \mathrm{min}$ via cooling unit.

\section{Formulation development of Modified}

\section{release Pellets}

\section{Preparation of the coated pellets (10)}

Fluidized bed processor is a method for the preparation of the coated pellets. In this method; a core material (sugar spheres) is coated with the drug substance following a secondary coating process in which the coating of gas forming agent and tertiary coating of modified release controlling polymer material is performed.

Table 2: Formulation of pellets

\begin{tabular}{|c|l|c|}
\hline Sr. No. & Ingredients (gms) & A1 \\
\hline 1 & Drug Loaded Pellets & 50 \\
\hline 2 & HPMC E5LVU.S.P. & 2 \\
\hline 3 & Sodium Bicarbonate AR & 8 \\
\hline 4 & PEG 6000 LR & 0.2 \\
\hline 5 & Isopropyl Alcohol AR & 25 \\
\hline 6 & Talc LR & 1.75 \\
\hline 7 & Purified water & 65 \\
\hline
\end{tabular}

Modified release coating

Coating was done by Eudragit coating. (11)

Table 3: Modified release coating on subcoated pellets

\begin{tabular}{|c|c|c|c|c|c|}
\hline $\begin{array}{c}\text { Sr. } \\
\text { No. }\end{array}$ & $\begin{array}{c}\text { Ingredients } \\
\text { (gms) }\end{array}$ & B1 & B2 & B3 & B4 \\
\hline 1 & $\begin{array}{c}\text { Sub coated } \\
\text { Pellets }\end{array}$ & 50 & 50 & 50 & 50 \\
\hline 2 & $\begin{array}{c}\text { Eudragit } \\
\text { NE 40D }\end{array}$ & 10 & 16.5 & 33.3 & 50 \\
\hline 3 & Talc LR & 1 & 1 & 1 & 1 \\
\hline 4 & $\begin{array}{c}\text { Purified } \\
\text { Water }\end{array}$ & 50 & 50 & 50 & 50 \\
\hline
\end{tabular}

Table 4: Process Parameters for modified release coat on drug coated pellets

\begin{tabular}{|c|l|l|}
\hline Sr.no. & Process parameters & Conditions \\
\hline 1 & Sub-coated pellets & $50 \mathrm{gms}$ \\
\hline 2 & Spray rate & $2.25 \mathrm{~g} / \mathrm{min}$ \\
\hline 3 & Atomizing air pressure & $1.2 \mathrm{bar}$ \\
\hline 4 & Product temperature & $23-26^{\circ} \mathrm{C}$ \\
\hline 5 & Inlet temperature & $32-35^{\circ} \mathrm{C}$ \\
\hline 6 & Fluidizing pressure & $0.45 \mathrm{bar}$ \\
\hline
\end{tabular}

Morphology of modified coated pellets (12) 
The morphology of non pareils was checked by SEM. The view of pellets showed a spherical structure with rough surface morphology (Figure 5).

\section{Micromeritic properties of modified coated pellets}

The micromeritic characteristics of pellets are shown in Table 5. The values of angle of repose and Hausner's ratio indicate excellent flowing properties. (12)

\section{Drug Content of modified coated pellets}

The drug content of modified release coated pellets is shown in Table 6 .

The friability of the Eudragit coated pellets was evaluated and values of friability test are shown in Table 6.

\section{Determination of floating behaviour of modified coated pellets}

All batches were prepared using Eudragit NE 40D; sodium bicarbonate was incorporated as a gas-generating agent in sub-coating layer. Effervescent layer induced $\mathrm{CO}_{2}$ generation in presence of release media $(0.01 \mathrm{~N} \mathrm{HCl})$. The Eudragit NE 40D was the permeable material, so when it came in contact with the $0.01 \mathrm{~N} \mathrm{HCl}$, by formation of pores the effervescent were created due to reaction of effervescent layer and $0.01 \mathrm{~N} \mathrm{HCl}$, thus decreasing density of spheroids. As density of spheres comes below 1, the spheres become buoyant. The floating lag time of various compositions B1-B4 (Preliminary batches) were shown to be in table 6

\section{In vitro Drug release studies of modified coated pellets}

In vitro drug release studies of Carvedilol from different pellets were done in $0.01 \mathrm{~N} \mathrm{HCl}$ using USP apparatus for dissolution test. In vitro releasing trials were checked in response to find the release of active substance from modified release pellets. Figure 6 shows the cumulative \% drug release of Eudragit NE 40D coated pellets. $(11,13)$

\section{Evaluation of formulation based optimization batches}

Micromeritic properties: The micromeritic properties of pellets are mentioned in Table 7 .

\section{Friability}

The friability of the Eudragit coated pellets was evaluated and values of friability test are shown in Table 8.

\section{Floating behaviour}

Floating behavior of Eudragit NE 40D coated was studied as like described in previous section and data given in table 8 .

\section{Drug Content}

The drug content of Eudragit coated pellets was found to be $95.00 \%-101.00 \%$ for batches F1 to F9.

\section{In vitro Drug release studies (14 - 16)}

The in vitro drug release behaviour of Eudragit NE 40D coated spheres was studied as like described in previous section and data given in table 9.

\section{RESULTS AND DISCUSSION}

\section{Pre-formulation Study}

\section{Melting point determination}

The melting point of Carvedilol was found 194$196^{\circ} \mathrm{C}$ which complies with the reported value.

\section{UV Spectrum of Carvedilol tartrate in $0.01 \mathrm{~N}$ $\mathrm{HCl}$}

UV spectrum of Carvedilol tartrate in $0.01 \mathrm{~N}$ $\mathrm{HCl}$ showed that the drug had a $\lambda_{\max }$ of 294.5 $\mathrm{nm}$ that was similar as reported.

\section{Standard curve of Carvedilol tartrate}

The standard plot of Carvedilol tartrate in $0.01 \mathrm{~N}$ $\mathrm{HCl}$ is shown in fig 11 . The correlation coefficient obtained was 0.997 and equation of regression line was $y=0.0375 x+0.0038$. The standard calibration data shows that the absorbance value increases linearly as the concentration increases. 


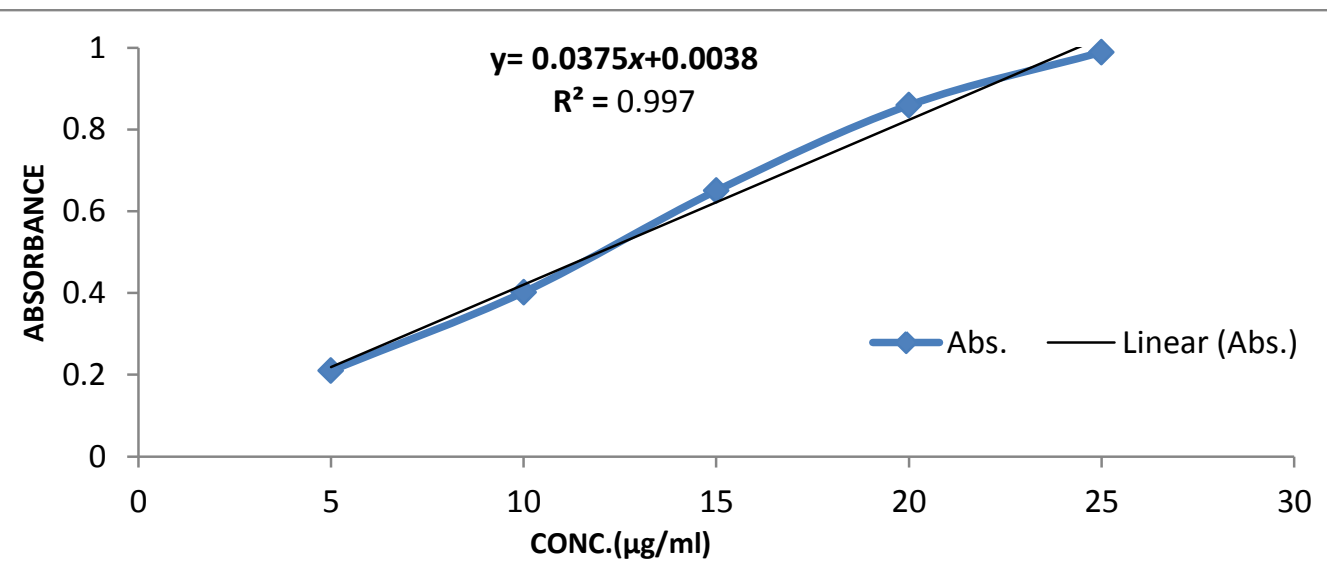

Figure 1: Standard Curve of Carvedilol tartrate in $0.01 \mathrm{~N} \mathrm{HCl}$.

\section{Drug-Excipients Interaction study}

\section{FTIR Spectroscopy:}

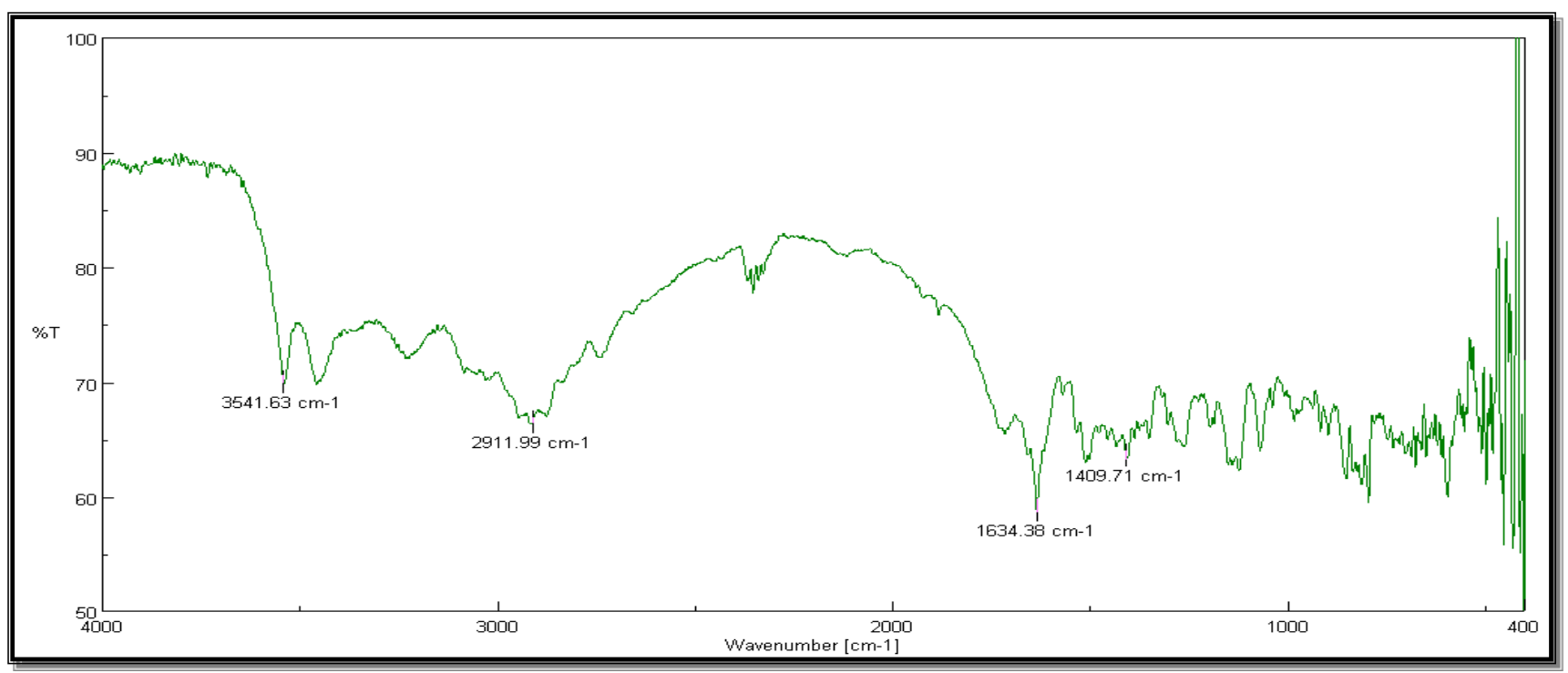

Figure 2: FTIR of Carvedilol +

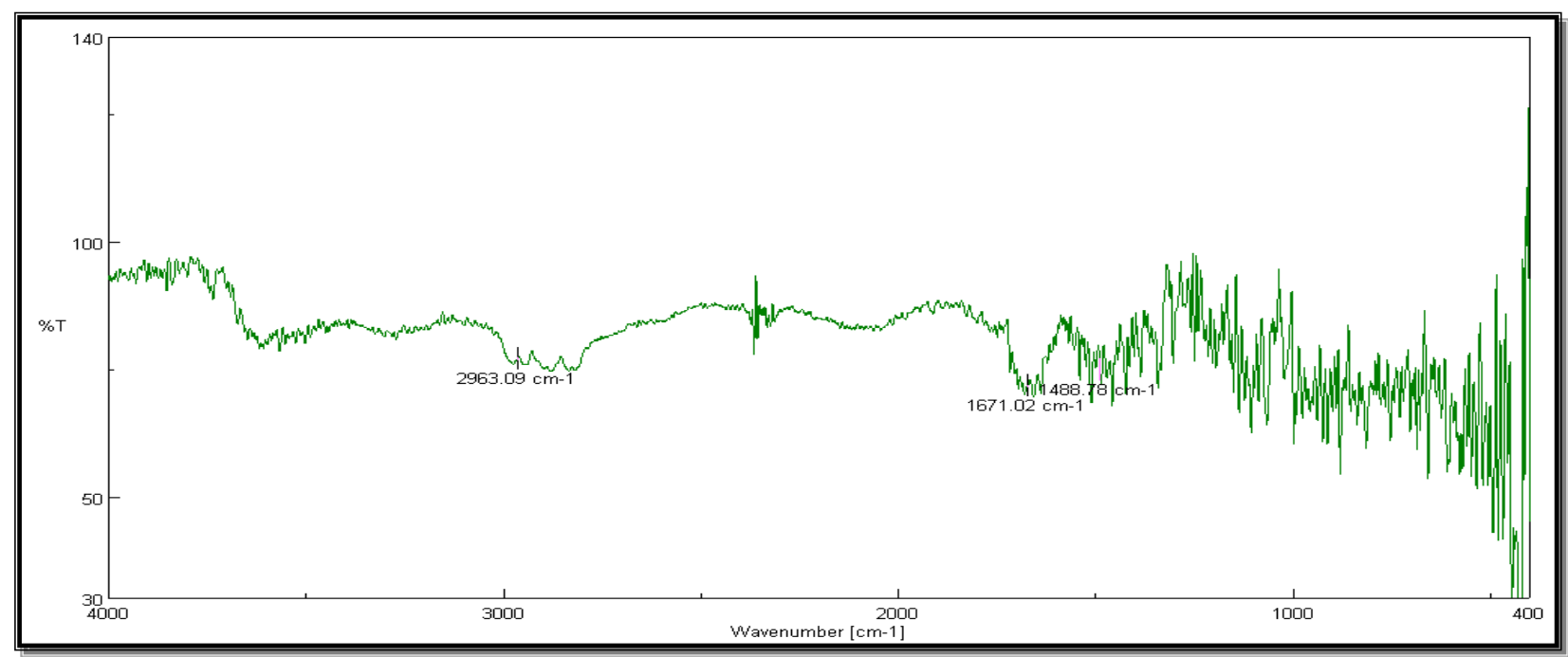

Figure 3: FTIR of Carvedilol + K30+SLS+ Eudragit NE 40D +Sodium bicarbonate +HPMC) 
The IR spectra of drug- excipients mixture shown that prominent peaks of the drug were un-affected or displayed from its original position. Thus no interaction was observe between the active substance and excipients. Hence drug-excipients compatibility was established. There was neither shift nor disappearance of properties peaks concludes that there is no any interaction in Carvedilol and other ingredients used in the formulation development or no degradation in drug molecule.

The FTIR spectra of active substance and the physical mixture with different ingredients confirmed no presence of the interaction between active substance and the other ingredients. It also assured that the grades of excipients used in formulation are compatible with Carvedilol.

On the basis of melting point and FTIR spectrum of drug it is observed that the procured Carvedilol was pure and it was free from any type of degradation product or any type of impurities.

\section{Differential Scanning Calorimetry}

DSC study was conducted to check the identity and purity of the Carvedilol.

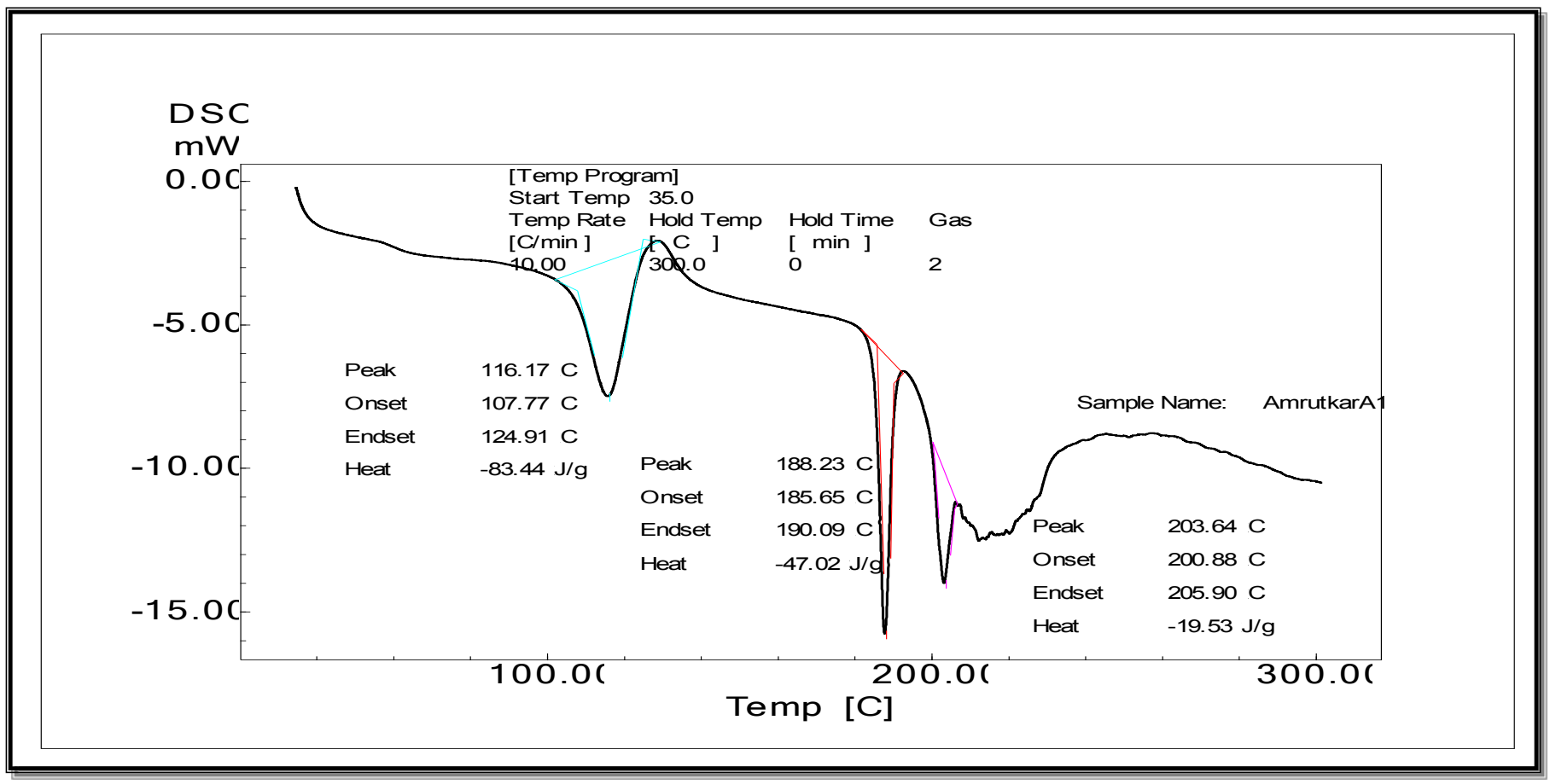

Figure 4: DSC of Carvedilol

On the basis of melting point, DSC study and FTIR spectrum of drug it is observed that the procured Carvedilol was pure and it was free from any type of degradation product or any type of impurities.

\section{Formulation development of Modified Release Pellets:}

Modified release coating was done by Eudragit coating.

\section{Micromeritic properties}

Table 5: Micromeritic properties of Eudragit coated pellets

\begin{tabular}{|c|c|c|c|}
\hline Formulation & $\begin{array}{c}\text { Bulk } \\
\text { density* } \\
\text { (gm/ml) }\end{array}$ & $\begin{array}{c}\text { Angle of } \\
\text { repose* }\end{array}$ & $\begin{array}{c}\text { Hausner } \\
\text { ratio* }^{*}\end{array}$ \\
\hline B1 & $0.791 \pm$ & $21.53 \pm$ & $1.08 \pm$ \\
& 0.128 & 0.102 & 0.258 \\
\hline B2 & $0.828 \pm$ & $20.93 \pm$ & $1.07 \pm$ \\
& 0.245 & 0.985 & 0.367 \\
\hline B3 & $0.833 \pm$ & $24.01 \pm$ & $1.01 \pm$ \\
& 0.218 & 0.374 & 0.158 \\
\hline B4 & $0.819 \pm$ & $23.58 \pm$ & $1.03 \pm$ \\
& 0.369 & 0.879 & 0.248 \\
\hline
\end{tabular}

$*$ Mean \pm S.D. $(n=3)$

The micromeritic characteristics of pellets are shown in Table 5. The values of angle of repose 
and hausner ratio indicate excellent flowing properties.

\section{Morphology of Eudragit coated pellets (modified release layered)}

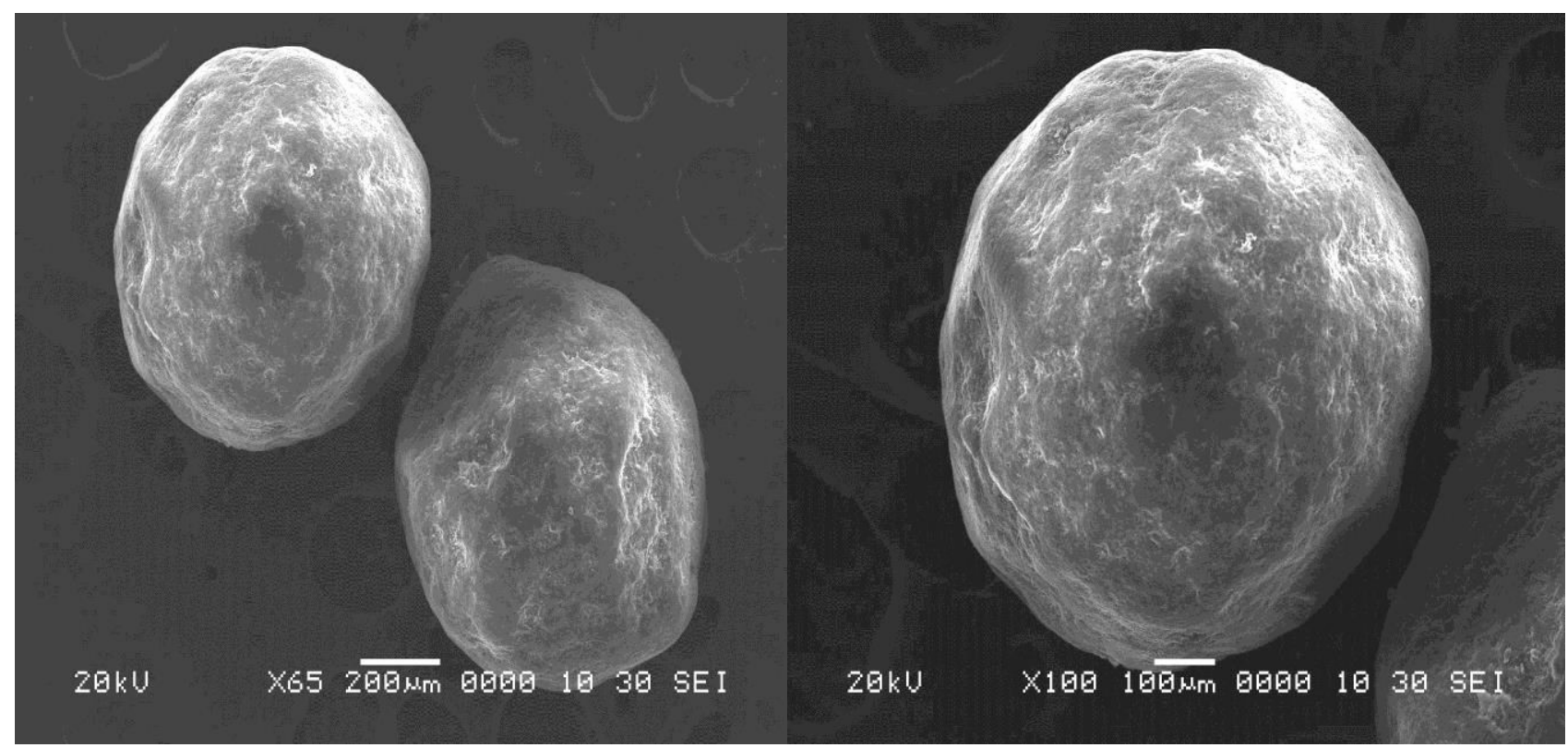

Figure 5: SEM Photograph of Eudragit coated pellets (modified release layered)

Friability of Eudragit coated pellets:

Table 6: Friability and Drug content of Eudragit coated pellets

\begin{tabular}{|c|c|c|c|}
\hline Formulation & Friability* (\%) & Drug content (\%) & Floating Lag Time* (FLT) (min) \\
\hline B1 & $0.09 \pm 0.102$ & $95.62 \pm 0.39$ & $17 \pm 1.0$ \\
\hline B2 & $0.198 \pm 0.143$ & $96.76 \pm 0.24$ & $24 \pm 1.2$ \\
\hline B3 & $0.135 \pm 0.215$ & $98.92 \pm 0.54$ & $29 \pm 2.5$ \\
\hline B4 & 0.1530 .125 & $98.59 \pm 0.15$ & $33 \pm 2.1$ \\
\hline
\end{tabular}

\section{Drug Content}

Drug content of Eudragit coated pellets were found out to be $95.00 \%-99.00 \%$ for B1 - B4. So the active substance content was found within the limit. The drug content of modified release coated pellets is shown in Table 6.

\section{Determination of floating behaviour of Eudragit coated pellets}

The floating lag time of various compositions B1-B4 (Preliminary batches) were shown to be in table 6.

\section{In vitro Drug release studies}

In vitro drug release studies of Carvedilol from different pellets were done in $0.01 \mathrm{~N} \mathrm{HCl}$ using USP apparatus for dissolution test.

The releasing profile of the active coating spheres is shown in Figure 6. The releasing profile of batches B1-B4 varies due to differences in the amount of Eudragit NE 40D. As higher the amount of Eudragit NE 40D the active unit release was lowered. In B1 trial it was shown that release of active unit after $10 \mathrm{~h}$. is $\approx 94.00 \%$ hence to enhance the active release up to $100 \%$, the further trials were planned by lowering spraying rate from $2.24 \mathrm{~g} / \mathrm{min}$. to 1.49 $\mathrm{g} / \mathrm{min}$. 


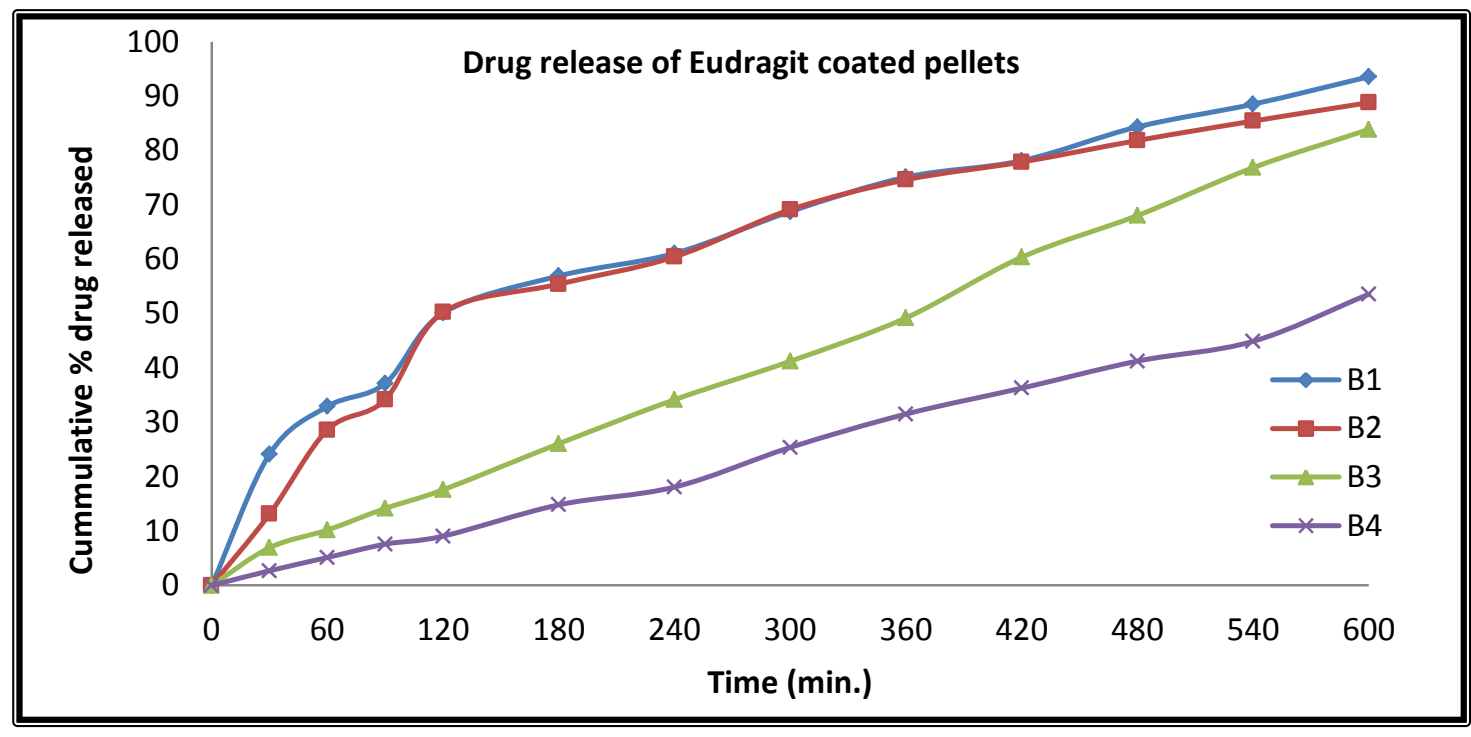

Figure 6: Drug release from Eudragit coated pellets

3. Evaluation of formulation based of Eudragit coated pellets were satisfactory. The optimization batches: values of angle of repose shows good flowing

The micromeritic properties of pellets are mentioned in Table 7. Micromeritic properties pattern of pellets.

Table 7: Micromeritic properties of Eudragit coated pellets

\begin{tabular}{|c|c|c|c|c|}
\hline Formulation & $\begin{array}{c}\text { Bulk density* } \\
(\mathbf{g m} / \mathbf{m l})\end{array}$ & $\begin{array}{c}\text { Tapped } \\
\text { Density* } \\
(\mathbf{g m} / \mathbf{m l})\end{array}$ & Angle of repose* & Hausner ratio* \\
\hline F1 & $0.91 \pm 0.69$ & $0.95 \pm 0.43$ & $27.03 \pm 0.58$ & $1.05 \pm 0.57$ \\
\hline F2 & $0.85 \pm 0.25$ & $0.77 \pm 0.63$ & $27.93 \pm 0.48$ & $0.91 \pm 0.61$ \\
\hline F3 & $0.75 \pm 0.78$ & $0.73 \pm 0.39$ & $28.58 \pm 0.67$ & $0.98 \pm 0.67$ \\
\hline F4 & $0.79 \pm 0.36$ & $0.53 \pm 0.61$ & $25.02 \pm 0.90$ & $0.68 \pm 0.61$ \\
\hline F5 & $0.80 \pm 0.15$ & $0.64 \pm 0.75$ & $26.13 \pm 0.61$ & $0.81 \pm 0.71$ \\
\hline F6 & $0.65 \pm 0.63$ & $0.55 \pm 0.17$ & $23.19 \pm 0.78$ & $0.85 \pm 0.63$ \\
\hline F7 & $0.85 \pm 0.12$ & $0.65 \pm 0.79$ & $24.09 \pm 0.37$ & $0.77 \pm 0.84$ \\
\hline F8 & $0.78 \pm 0.39$ & $0.83 \pm 0.52$ & $25.01 \pm 0.64$ & $1.07 \pm 0.37$ \\
\hline F9 & $0.95 \pm 0.58$ & $0.76 \pm 0.23$ & $25.98 \pm 0.53$ & $0.81 \pm 0.82$ \\
\hline
\end{tabular}

\section{Friability}

The results for friability test are shown in Table 8. All the pellet compositions achieved friability figures minimum than $0.30 \%$. Thus all spheres passed the USP friability test.

\section{Floating behavior of formulations}

All batches (F1 to F9) were manufactured utilizing Eudragit NE 40D. Effervescent agents were incorporated as a gas-generating agent in sub-coating layer. Effervescent agent induced $\mathrm{CO}_{2}$ generation in presence of drug release media $(0.01 \mathrm{~N} \mathrm{HCl})$. The effervescences were created due to reaction of effervescent agent and $0.01 \mathrm{~N} \mathrm{HCl}$, thus reducing the density of spheres. As the density of spheres goes below 1, the spheres become buoyant.

All tablet batches (F1 to F9) exhibited satisfactory floatation ability and remain buoyant for more than $10 \mathrm{hrs}$ in dissolution media $(0.01 \mathrm{~N} \mathrm{HCl})$. Floating lag time (FLT) for all batches (F1 to F9) was found to be 06 - 35 min (Table 8 ). These results show that buoyancy lag-time was satisfactory. 
Table 8: Friability and Floating lag time (FLT) and drug content of different formulations

\begin{tabular}{|c|c|c|c|}
\hline Formulation & Friability* (\%) & Floating lag time* (FLT) (min) & Drug content* (\%) \\
\hline F1 & $0.238 \pm 0.637$ & $09 \pm 1.2$ & $99.54 \pm 0.25$ \\
\hline F2 & $0.221 \pm 0.419$ & $08 \pm 1.5$ & $100.27 \pm 0.69$ \\
\hline F3 & $0.193 \pm 0.527$ & $17 \pm 2.3$ & $98.89 \pm 0.64$ \\
\hline F4 & $0.213 \pm 0.478$ & $16 \pm 1.1$ & $97.56 \pm 0.96$ \\
\hline F5 & $0.253 \pm 0.378$ & $13 \pm 2.4$ & $95.97 \pm 0.35$ \\
\hline F6 & $0.186 \pm 0.948$ & $12 \pm 3.1$ & $96.37 \pm 0.69$ \\
\hline F7 & $0.259 \pm 0.618$ & $24 \pm 2.5$ & $98.28 \pm 0.14$ \\
\hline F8 & $0.221 \pm 0.371$ & $29 \pm 1.4$ & $97.19 \pm 0.58$ \\
\hline F9 & $0.191 \pm 0.318$ & $33 \pm 1.5$ & $96.79 \pm 0.74$ \\
\hline
\end{tabular}

*Mean \pm S.D. $(n=3)$

\section{Drug Content}

The drug content of Eudragit coated pellets was found to be $95.00 \%-101.00 \%$ for batches F1 to F9. The friability of the Eudragit coated pellets was evaluated and results obtained were in range of $0.09-0.20 \%$. All pellet compositions achieved friability figures minimum than $0.20 \%$. The spheres were coated with Eudragit NE 40D as release controlling polymer, coating performed using Eudragit NE 40D have high tensile strength. Thus all spheres passed USP friability test. $(14,15)$ Values of friability test are shown in Table 8 .

\section{In vitro Drug release studies}

In vitro drug release study of active unit from various spheres was performed in $0.01 \mathrm{~N} \mathrm{HCl}$ utilizing USP apparatus for dissolution test. In vitro release trials were studied in order to check the drug release. The in vitro drug release behavior of Eudragit NE 40D coated spheres was given in table 9 .

Table 9: Dissolution study of F1-F9 Formulation

\begin{tabular}{|c|c|c|c|c|c|c|c|c|c|}
\hline \multirow{2}{*}{$\begin{array}{c}\text { Time } \\
(\mathbf{m i n})\end{array}$} & \multicolumn{8}{|c|}{ Cumulative \% Drug Release* } \\
\cline { 2 - 11 } & F1 & F2 & F3 & F4 & F5 & F6 & F7 & F8 & F9 \\
\hline 30 & $23.19 \pm$ & 6.67 & 3.28 & 18.29 & 4.19 & 4.11 & 13.13 & 6.93 & 2.69 \\
& 0.12 & \pm 0.74 & \pm 0.58 & \pm 0.84 & \pm 0.25 & \pm 0.12 & \pm 0.28 & \pm 0.63 & \pm 0.35 \\
\hline 60 & 36.82 & 12.28 & 8.18 & 32.22 & 10.13 & 7.58 & 28.60 & 10.19 & 5.13 \\
& \pm 0.36 & \pm 0.68 & \pm 0.34 & \pm 0.34 & \pm 0.25 & \pm 0.35 & \pm 0.68 & \pm 0.45 & \pm 0.38 \\
\hline 90 & 44.64 & 16.54 & 13.87 & 38.89 & 16.31 & 10.15 & 34.21 & 14.16 & 7.59 \\
& \pm 0.15 & \pm 0.15 & \pm 0.32 & \pm 0.72 & \pm 0.36 & \pm 0.27 & \pm 0.38 & \pm 0.37 & \pm 0.91 \\
\hline 120 & 57.18 & 20.23 & 18.34 & 53.3 & 21.83 & 13.17 & 50.24 & 17.59 & 9.06 \\
& \pm 0.847 & \pm 0.54 & \pm 0.25 & \pm 0.35 & \pm 0.24 & \pm 0.35 & \pm 0.45 & \pm 0.85 & \pm 0.37 \\
\hline 180 & 62.03 & 30.90 & 25.20 & 55.55 & 29.54 & 19.29 & 55.43 & 26.07 & 14.82 \\
& \pm 0.24 & \pm 0.17 & \pm 0.27 & \pm 0.41 & \pm 0.58 & \pm 0.15 & \pm 0.52 & \pm 0.45 & \pm 0.51 \\
\hline 240 & 72.67 & 40.70 & 31.71 & 63.5 & 40.35 & 23.69 & 60.45 & 34.17 & 18.09 \\
& \pm 0.42 & \pm 0.62 & \pm 0.36 & \pm 0.38 & \pm 0.35 & \pm 0.68 & \pm 0.62 & \pm 0.34 & \pm 0.51 \\
\hline 300 & 79.61 & 50.56 & 39.58 & 70.7 & 49.57 & 31.85 & 69.12 & 41.24 & 25.38 \\
& \pm 0.39 & \pm 0.15 & \pm 0.24 & \pm 0.62 & \pm 0.47 & \pm 0.14 & \pm 0.36 & \pm 0.89 & \pm 0.24 \\
\hline 360 & 82.93 & 63.58 & 47.39 & 77.45 & 60.99 & 38.74 & 74.62 & 49.42 & 31.52 \\
& \pm 0.15 & \pm 0.34 & \pm 0.24 & \pm 0.15 & \pm 0.49 & \pm 0.34 & \pm 0.24 & \pm 0.65 & \pm 0.71 \\
\hline 420 & 87.3 & 71.64 & 55.08 & 82.51 & 70.11 & 43.37 & 77.89 & 60.37 & 36.29 \\
& \pm 0.14 & \pm 0.48 & \pm 0.35 & \pm 0.36 & \pm 0.32 & \pm 0.16 & \pm 0.63 & \pm 0.26 & \pm 0.61 \\
\hline 480 & 92.66 & 82.29 & 63.31 & 86.32 & 78.13 & 50.55 & 81.85 & 68.04 & 41.26 \\
\hline
\end{tabular}




\begin{tabular}{|c|c|c|c|c|c|c|c|c|c|}
\hline & \pm 0.25 & \pm 0.58 & \pm 0.79 & \pm 0.34 & \pm 0.51 & \pm 0.85 & \pm 0.37 & \pm 0.91 & \pm 0.71 \\
\hline 540 & 96.14 & 90.96 & 69.72 & 91.07 & 88.16 & 57.56 & 85.43 & 76.85 & 44.900 \\
& \pm 0.36 & \pm 0.358 & \pm 0.84 & \pm 0.21 & \pm 0.53 & \pm 0.78 & \pm 0.17 & \pm 0.37 & \pm 0.529 \\
\hline 600 & 99.98 & 98.19 & 78.62 & 96.25 & 92.31 & 62.59 & 88.81 & 83.88 & 53.57 \\
& \pm 0.58 & \pm 0.14 & \pm 0.35 & \pm 0.35 & \pm 0.51 & \pm 0.91 & \pm 0.63 & \pm 0.28 & \pm 0.23 \\
\hline
\end{tabular}

*Mean \pm S.D. $(\mathrm{n}=3)$

It was observed that all compositions show release of drug more than $80 \%$ in $10 \mathrm{hrs}$ except F6 and F9 because in both formulations highest concentration of Eudragit NE 40D was used.

\section{SUMMARY \& CONCLUSION}

The modified release pellets were prepared by the sub-coating with HPMC 5 cps and sodium bicarbonate which was used to retain the pellets in stomach for prolong time. To achieve modified release of active substance from spheres, the sub coated spheres were coated with methacrylic acid polymer (Eudragit NE 40D). Hence HPMC 5cps, sodium bicarbonate and Eudragit NE 40D are the key excipients of this research work.

The process based optimization study also carried out to optimize process parameters like spray rate and product temperature to enhance physical appearance and micromeritic properties of pellets by preliminary studies. The pellets were checked for physical parameters like appearance, bulk density, tapped density, hausner's ratio and angle of repose. The pellets were checked for friability, content of drug and In-vitro release studies. The results of all the tests carried out, were found satisfactory.

The drug Carvedilol can be formulated in a modified release pellets using optimum concentration of key excipients and optimum process parameters. Following conclusions may be drawn from the study:

- Optimum concentration of HPMC 5cps and PVP K30 during drug layering shows better physical and chemical properties of pellets

- Optimum ratio of HPMC: Sodium Bicarbonate during sub-coating shows better stomach retention properties.

- Methacrylic acid polymers (Eudragit NE 40D) due to its hydrophilic and hydrophobic characteristics and ease of application provides desired drug release pattern, when utilized in optimum quantity during modified release coating.

- The factorial design and optimization studies serve as better tool for selecting suitable formulation for desired drug release kinetics.

- The optimization studies serve as better tool for arriving at suitable process parameters for desired physical properties of pellets.

- The optimized formulation was stable in the accelerated stability studies.

\section{ACKNOWLEDGEMENTS}

The authors are thankful to IJDRA journal for publishing our article.

\section{CONFILCTS OF INTEREST}

The authors declare that there are no conflicts of interest.

\section{REFERENCES}

1. Rastogi V, Shukla S, Singh R, Lal N, \& Yadav P. Microspheres: a promising drug carrier. Journal of Drug Delivery and Therapeutics. 2016; 6(3):18-26. doi:10.22270/jddt.v6i3.1196

2. Kappor D, Patel M, Vyas R, Lad C, \& Tyagi B. A review on microsponge drug delivery system. Journal of Drug Delivery and Therapeutics. 2014; 4(5):29-35. doi:10.22270/jddt.v4i5.978

3. Kapoor D. Fabrication and characterization of nonsteroidal anti-inflammatory alginate beads for sustained release using natural polymer. Journal of Drug Delivery and Therapeutics. 2017; 7(2):77-80. doi:10.22270/jddt.v7i2.1401

4. Thakkar H, Patel N, Amodwala S. Formulation development of controlled release mucoadhesive beads of capecitabine. Journal of Drug Delivery and Therapeutics. 2016; 6(3):42-50. doi:10.22270/jddt.v6i3.1252

5. Kajale A, Chandewar A. Formulation and evaluation of oral floating beads of tramodol hydrochloride. Journal of Drug Delivery and Therapeutics. 2016; 6(4):7-16. doi:10.22270/jddt.v6i4.1270 
6. Shaji J, Chadawar V, Talwalkar P. Multiparticulate Drug transport system. The Indian Pharmacist. 2007; 6(60):21-28.

7. Zhang Z. Multi-Component Drug Delivery of Paclitaxel. Journal of Drug Delivery and Therapeutics. 2017; 7(3):80-83. doi:10.22270/jddt.v7i3.1451.

8. Laila F, Chandran S. Multiparticulate formulation method to colon specific drug delivery cutting-edge perspectives. J. Pharm Pharm Sci. 2006; 9(3):327-38.

9. Shah D, Patel B, Shah C. Nanosuspension technology: a innovative slant for drug delivery system and permeability enhancer for poorly water soluble drugs. Journal of Drug Delivery and Therapeutics. 2015; 5(1):10-23. doi:10.22270/jddt.v5i1.995.

10. Schmidt C, Bodmeier R. A multiparticulate drugtransport system based totally on pellets included into congealable polyethylene glycol carrier substances. Int. J. Pharm. 2001; 216: 9-16.

11. Mehta AM, Valazza MJ, Abele SE. Evaluation of fluidized-mattress methods for enteric coating systems. Pharm. Technology. 1986; 46- 48.

12. Agarwal D, Ranawat M, Chauhan C, Kamble R. Formulation and characterisation of colon targeted $\mathrm{pH}$ dependent microspheres of capecitabine for colorectal cancer. Journal of Drug Delivery and Therapeutics. 2014; 3(6):215-22. doi:10.22270/jddt.v3i6.747

13. Patil S, Gupta V. Design and in vitro evaluation of multiparticulate system for the chronomodulated delivery of lornoxicam. Journal of Drug Delivery and Therapeutics. 2015; 5(3):62-71.

doi:10.22270/jddt.v5i3.1148

14. Thoma okay, Ziegler I. The $\mathrm{pH}$ independent release of fenoldopam from pellets with insoluble film coats. Eur J Pharm and Biopharm. 1998; 47(1):105-13.

15. Umprayn OK, Chitropas $\mathrm{P}$, Amarekajorn S. Development of terbutaline sulphate sustained release lined pellets. Drug Dev. Ind. Pharm. 1999; 25(4):47791.

16. Weijia Z, Mcginity J. Impact of Eudragit@ NE 30 D blended with Eudragit ${ }^{\circledR}$ L 30 D-55 on the discharge of phenylpropanolamine hydrochloride from covered pellets. Drug Dev. Ind. Pharm. 2003; 29(3):357-366. 